\section{Adolescentes como voluntários de pesquisa e consentimento livre e esclarecido: conhecimento e opinião de pesquisadores e jovens}

\author{
Adolescents as research subjects and free \\ informed consent: knowledge and opinion \\ of researchers and adolescents
}

Fabiana Guariglia 1 Silvana Ferreira Bento 2 Ellen Hardy 1

\section{Introdução}

This article presents the results of a study that evaluated the knowledge and opinions of researchers and adolescents that served as their research subjects on the legal norms that regulate the participation of the latter as research subjects, the capacity of adolescents to make autonomous decisions regarding participation, and the adolescent experience after agreeing to take part in a study. This was a qualitative study with a convenience sample, the size of which was defined by the criteria of informational redundancy. Interviews were conducted with three researchers who had used adolescents as research subjects and nine of these subjects. This number of interviews was sufficient to reach informational redundancy. Data was collected through recorded semistructured interviews, with open questions. All the researchers were familiar with some legal document related to the participation of adolescents as subjects of research. On the other hand, the adolescents were surprised because they were not aware of the existence of such documents. However, they considered them necessary for their own protection. In general, researchers and adolescents believe that adolescents have the capacity to decide autonomously to participate as research subjects. The adolescents affirmed that they had decided to volunteer conscientiously.

Adolescent; Ethics Research; Informed Consent
Uma em cada cinco pessoas no mundo tem entre 10 e 19 anos de idade - faixa etária que corresponde à adolescência segundo a Organização Mundial da Saúde (OMS) 1. No Brasil, essa é a faixa de idade de maior proporção, de acordo com o censo demográfico realizado pelo Instituto Brasileiro de Geografia e Estatística em 2000 2. Esses jovens são vítimas de vários problemas, tais como a gravidez indesejada, contaminação por DST (inclusive HIV) e mortes por trauma.

Conseqüentemente, tem-se multiplicado a necessidade de pesquisas que identifiquem fatores associados a esses problemas e os expliquem. No entanto, os pesquisadores interessados em fazer pesquisas com adolescentes não sabem como agir pela falta de clareza nos documentos que regulamentam os estudos com pessoas nessa faixa etária. Faltam informações quanto à autonomia e capacidade dos mesmos para dar seu consentimento informado.

O consentimento informado é uma das exigências presentes nas normas e regulamentações $3,4,5$ para realizar pesquisa com seres humanos, existentes para proteger os sujeitos das pesquisas de possíveis abusos. Uma das abordagens bioéticas é o principalismo ${ }^{6}$, que se baseia, resumidamente, em quatro princípios: autonomia (ou respeito à pessoa), beneficência, não maleficência e justiça. 
A obtenção do consentimento informado é uma tentativa de preservação do princípio da autonomia. Essa tentativa, em pesquisas envolvendo crianças e adolescentes, é observada quando a Resolução196/96 4 (p. 19) orienta que se deve "cumprir as exigências do consentimento esclarecido, através dos representantes legais". Entretanto, não foi encontrada uma norma nacional, que tenha poder de veto, específica para a participação de adolescentes em pesquisa. A Resolução 196/96 4 bem como outros documentos identificados 3,7 referem-se apenas às crianças ou às crianças e adolescentes como sinônimos. Além disso, é comum ser utilizada a palavra "children" tanto para crianças quanto para adolescentes.

Pensando nisso, a Society for Adolescent Medicine elaborou um guia sobre a realização de pesquisas com esse grupo específico ${ }^{8}$. Segundo esse, para realizar estudos com adolescentes, deve ser considerada a necessidade de equacionar a emergente independência para tomar decisões e a - ainda existente - necessidade de proteção desses indivíduos potencialmente vulneráveis. No Brasil, os casos em que o consentimento informado deve ser dado pelos representantes legais dos sujeitos - através da assinatura do Termo de Consentimento Livre e Esclarecido (TCLE) - são aqueles cujos voluntários de pesquisa são civilmente incapazes 4 .

Para definir quem é incapaz, a Resolução remete à legislação brasileira, ou seja, ao Código Civil 9. Os artigos 3o e 4o do Código Civil dividem os menores em dois grupos segundo sua incapacidade. O primeiro inclui os menores de 16 anos, que são considerados absolutamente incapazes (Artigo 3o, I). Esses indivíduos devem ser representados em seus atos da vida civil. O segundo é formado pelos maiores de $16 \mathrm{e}$ menores de 18 anos de idade, que são classificados como relativamente incapazes a certos atos da vida civil ou à maneira de exercê-los (Artigo 4o, I). As pessoas que se encontram nesse grupo devem ser assistidas em seus atos 9. Entretanto, o Código Civil não define os atos em que esses menores são relativamente incapazes.

Isso leva a uma dificuldade para o desenvolvimento de pesquisas em que os participantes são maiores de 16 e menores de 18 anos de idade. Caso a participação como sujeito de uma pesquisa faça parte dos "atos da vida civil" para os quais os jovens são relativamente incapazes, os que se encontram nessa faixa etária deveriam dar seu consentimento juntamente com seu representante legal.

Entretanto, há outros aspectos a serem questionados como a autonomia. Autonomia deriva do grego auto - que significa próprio - e no- mos - que significa lei, regra, norma. Porém, existem diferentes concepções desse conceito. A tradição kantiana a define como constitutiva do indivíduo e está relacionada à liberdade individual e à vontade. Já para os utilitaristas, ela tem bases no agir útil, e não na vontade. Para Émile Durkheim, autonomia é a interiorização das normas 10,11. Entretanto, alguns pontos são comuns nas várias definições de autonomia: a liberdade e a ação 10 .

Esse conceito está relacionado à capacidade de autodeterminação. Esta é fundamental para a obtenção do consentimento informado. A dificuldade, porém, é definir essa capacidade no indivíduo. Em geral, considera-se o adulto capaz; e apenas quando ele se contrapõe aos argumentos e procedimentos dos profissionais é que se questiona a sua capacidade. E o caso dos adolescentes? É possível decidir quando o adolescente adquiriu as características que o tornam um ser autônomo? Há situações em que os adolescentes podem tomar decisões por si próprios? Frente a essas indagações, a autonomia do adolescente para a tomada de decisão deve ser avaliada individualmente 12 .

Essa ausência de definições dificulta a inclusão de adolescentes em pesquisas, pois não está claro se podem consentir sozinhos ou até que ponto são necessárias a autorização e assinatura de um responsável legal no TCLE. Este trabalho apresenta resultados de um estudo que avaliou o conhecimento e a opinião de pesquisadores e de jovens sobre as normas legais referentes à participação de adolescentes como sujeitos de pesquisa; a opinião sobre a capacidade dos adolescentes decidirem de forma autônoma; e o processo vivenciado quando aceitaram serem sujeitos da pesquisa.

\section{Sujeitos e métodos}

Foi realizado um estudo qualitativo utilizando entrevistas semidirigidas para obtenção da informação. A amostra foi intencional, incluindo duas categorias de participantes, pesquisadores e jovens, selecionados em função do seu conhecimento e experiência relacionados à participação de adolescentes como sujeitos de pesquisa. O tamanho amostral foi definido pelo critério de saturação das informações 13,14. Foram entrevistados três pesquisadores, sendo cada um responsável por uma pesquisa, e três jovens participantes de cada pesquisa, totalizando nove jovens. Ao completar esse número de entrevistas, observou-se que o mesmo era suficiente para cumprir o critério de saturação, entretanto, caso fosse necessário, novos sujei- 
tos seriam selecionados. O termo “jovem” foi utilizado, pois suas idades variavam entre $16 \mathrm{e}$ 21 anos de idade, o que significa que nem todas eram adolescentes por ocasião da entrevista 1 . Embora não fosse critério de inclusão, por coincidência, todos os participantes deste estudo foram do sexo feminino, e todas as pesquisas, nas quais as voluntárias estavam envolvidas, relacionavam-se ao pré-natal, parto, puerpério. Isto dá uma certa especificidade aos resultados, não permitindo generalizar para pesquisadores e adolescentes de sexo masculino nem para jovens não grávidas.

Os seguintes critérios foram utilizados para a seleção: (a) inclusão da pesquisadora - estar realizando ou ter realizado, nos dois anos anteriores à entrevista, uma pesquisa que incluiu indivíduos que ela considera/considerou adolescentes. (b) Inclusão da jovem - ser indicada pela pesquisadora entrevistada; estar participando ou ter participado, nos dois anos anteriores à entrevista, como voluntária de uma pesquisa; ter sido considerada adolescente pela pesquisadora; pais ou responsáveis legais terem conhecimento sobre sua participação na pesquisa; ter 16 anos de idade ou mais quando participou da pesquisa. Com a escolha dessa faixa etária, excluíram-se os menores considerados absolutamente incapazes.

As pesquisadoras foram selecionadas segundo a técnica "bola de neve" 14 . A investigadora entrou em contato com as pessoas indicadas por outros pesquisadores, através de telefone ou correspondência eletrônica. Elas foram informadas sobre o estudo e responderam algumas perguntas para identificar aquelas que cumpriam os critérios de inclusão. Estas foram convidadas a participar. Quando aceitavam, era combinado o local, dia e hora em que preferiam ser entrevistadas.

Ao término da entrevista com cada pesquisadora, a investigadora solicitou que selecionasse, através de sorteio com uma tabela de dígitos aleatórios 15, três adolescentes_admitidas na sua pesquisa. Em seguida, era verificado se cumpriam os critérios de inclusão. As que cumpriam foram contatadas pela pesquisadora, que perguntou se aceitavam que a investigadora falasse com elas. As que aceitavam indicavam como deveria ser feito o primeiro contato. Durante o mesmo, a investigadora as convidava para participar deste estudo e combinavam o local, dia e hora em que seria realizada a entrevista.

A técnica da entrevista semidirigida implica em utilizar um roteiro de perguntas abertas relacionadas ao tema de interesse 16 . Cada voluntária foi entrevistada individualmente pela investigadora. As entrevistas foram gravadas utilizando dois gravadores simultaneamente. As gravações foram transcritas por uma pessoa e conferidas, numa segunda leitura, pela investigadora. Em seguida, o conteúdo de cada entrevista foi inserido no programa computacional The Ethnograph v. 5.0. A análise dos dados seguiu o modelo metodológico proposto por Minayo 17. Foi realizada uma análise temática que implica em "descobrir os núcleos de sentido que compõem uma comunicação cuja presença ou freqüência signifiquem alguma coisa para o objetivo analítico visado" 17 (p. 209).

O projeto foi aprovado pelo Comitê de Ética em Pesquisa da Faculdade de Ciências Médicas, Universidade Estadual de Campinas. Todas as participantes do estudo, bem como seus responsáveis legais, assinaram o TCLE, ficando uma cópia para si e outra com a investigadora.

\section{Resultados e discussão}

A forma como foi feito o convite para as adolescentes participarem na pesquisa, o processo seguido para obter seu consentimento livre e esclarecido, bem como quem assinou o TCLE são descritos a seguir.

Pesquisa 1: a primeira consulta de pré-natal das adolescentes foi agendada com a pesquisadora, pois a pesquisa se desenvolveu no ambulatório em que trabalhava. Durante essa consulta, foi explicado que se estava realizando uma pesquisa e era entregue uma cópia do termo. Era solicitado que cada uma o lesse e, se concordasse na participação, que fosse assinado por ela e pelo acompanhante (se fosse o caso). Só então respondia as perguntas do questionário e realizava as outras atividades exigidas pela pesquisa.

Pesquisa 2: o convite para participar foi realizado por uma assistente, no quarto da maternidade, durante o pós-parto. Neste momento, as adolescentes receberam informações sobre a pesquisa, e às que aceitaram participar, foram entregues duas cópias do termo para levarem para casa. As menores de 18 anos e que disseram não serem casadas eram orientadas a respeito da necessidade dos pais ou responsáveis assinar o termo juntamente com elas. Entre 45 a 60 dias depois, a assistente comparecia à residência da adolescente, novamente explicava sobre a pesquisa, conversava com o responsável (se fosse o caso) e solicitava que lhe entregasse uma cópia do termo assinado. A seguir, realizava a entrevista.

Pesquisa 3: primeiramente, a pesquisadora identificou as mães que tinham entre 13 e 18 
anos de idade e que moravam na região que correspondia ao distrito de saúde selecionado. Ela ou uma das assistentes foi na residência de cada uma das mães. Explicava sobre a pesquisa que estava sendo realizada e fazia o convite para participar. Caso aceitasse, era solicitado que o responsável assinasse o termo juntamente com a adolescente. Caso dissesse ser casada, apenas ela assinava o termo. Em seguida, era realizada a entrevista.

Com relação ao processo vivenciado ao dar o consentimento, foi perguntado às jovens sobre como ficaram sabendo da pesquisa; se alguém havia explicado os objetivos da mesma; se haviam assinado um termo e se lembravam os conteúdos do mesmo. Freqüentemente, as jovens não se recordavam e não sabiam responder sobre alguns dos itens. O local e o momento em que o convite foi feito, bem como o fato de as explicações terem sido dadas mais de uma vez estiveram relacionadas com o que elas se lembravam de terem sido informadas. As que se recordaram melhor foram aquelas em que o convite e as explicações foram dados durante a internação no hospital e, novamente, depois nas suas casas. Uma provável interpretação para esse dado é o fato de o consentimento informado ter sido obtido sob a ótica de um processo, e não simplesmente como o cumprimento de uma etapa da pesquisa através da assinatura do TCLE 18

Apenas duas jovens relataram ter assinado o termo juntamente com algum responsável, apesar de grande parte ter menos de 18 anos de idade na época em que participou da pesquisa. Uma delas não se recordou de ter assinado o termo. As participantes mencionaram poucos assuntos quando perguntadas sobre o conteúdo do termo. Autorização, voluntariedade, sigilo, objetivos, riscos e benefícios foram alguns dos assuntos lembrados, mas nenhuma citou dois ou mais assuntos, ou seja, se lembraram apenas de um deles.

$\mathrm{O}$ fato de as pesquisadoras e as jovens terem assinado um TCLE para participar do estudo pode ter sugerido as respostas. Essa possibilidade também foi apontada por Hardy et al. 19 no artigo em que se apresentam resultados sobre a forma como os pesquisadores haviam obtido o consentimento informado, pois as autoras também os convidaram a participar utilizando um TCLE.

Além de informarem sobre o que se recordavam da sua participação na pesquisa, elas relataram os motivos que as levaram a aceitar participar da pesquisa, entre os quais predominou o desejo de colaborar e de se informarem. Outras razões foram não ter motivos para recu- sar e terem sido bem tratadas e ouvidas pela pesquisadora. Uma jovem aceitou pois foi influenciada pela tia que a estava acompanhando e porque teve vergonha de se recusar: “... ela [a pesquisadora] só falou assim pra mim: que tinha que fazer. Eu falei que tudo bem porque eu não tinha nada contra, e ela me deu muito conselho sobre minha gravidez" (J.1.2). "Eu fiquei meio em dúvida se eu participava ou não, e ela [tia] falou: vai não custa nada fazer. Aí eu peguei e fiz. (...) Eu acho que mais porque eu fiquei com vergonha de falar que não. Não é bem porque eu queria" (J.1.3).

Uma discussão constantemente abordada é a questão da relação de poder entre pesquisador e voluntário de pesquisa. A Resolução 196/96 4 mostra essa preocupação ao definir o consentimento livre e esclarecido como a anuência do sujeito de pesquisa livre de subordinação, dependência ou intimidação. Porém, essa relação é desde sua origem desigual, uma vez que (geralmente) é o pesquisador quem procura o voluntário. Essa desigualdade pode se acentuar quando o voluntário de pesquisa é ao mesmo tempo paciente 18. Esse aspecto, em um país como o Brasil onde os indivíduos aguardam um tempo excessivo para serem atendidos pelas instituições públicas de saúde, pode se acentuar uma vez que, em geral, as pesquisas ocorrem nessas instituições. Em uma sociedade em que há maior dependência dos membros frente às autoridades, no caso os pesquisadores, a voluntariedade pode ser substituída por obediência 18. Esse aspecto pode ser observado nas falas das pesquisadoras, que apontaram para o fato de algumas adolescentes não terem autonomia para se negar a participar da pesquisa: “... elas talvez não tinham autonomia, nesse momento, para dizer não. Não se sentiram obrigadas, mas, também, eu acho que elas não tinham motivo para dizer não" (P.1).

Cabe ao pesquisador esforçar-se para reduzir a desigualdade de poder, ele deve tentar garantir que a pessoa tenha aceitado participar pelo desejo de fazê-lo, e não apenas pela ausência de motivos para se negar ou por vergonha de se recusar a participar. Portanto, a obtenção do consentimento esclarecido deve basear-se na autonomia e na autodeterminação do indivíduo. Sem a presença desses aspectos, a validade do consentimento é questionável 18 . Logo, não é suficiente conhecer e seguir as normas para a realização de pesquisa; é preciso compreendê-las em profundidade. 
Conhecimento sobre normas para a realização de pesquisas com adolescentes

Todas as pesquisadoras citaram a Resolução 196/96 4, porém uma delas mencionou também o Estatuto da Criança e do Adolescente 20 e o Código Civil 9 . Apesar de somente a Resolução fazer referência à participação de adolescentes em pesquisa (Capítulo IV, item 3a), ela baseiase no Código Civil 9 e no Estatuto da Criança e do Adolescente 20. Também foi perguntado às jovens se conheciam ou se tinham ouvido falar a respeito de alguma regra ou norma a ser cumprida pelos pesquisadores quando fazem pesquisas cujos voluntários são adolescentes, após terem sido informadas pela investigadora a respeito da existência das mesmas. Apenas uma disse que foi informada sobre esse aspecto quando convidada a participar da pesquisa. Elas não imaginavam o conteúdo dessas normas ou regras, entretanto, as consideraram necessárias para proteger os adolescentes.

Uma delas disse que não achava muito necessárias as normas, e sim que o pesquisador saiba como falar com adolescentes: "pra conversar com adolescentes sempre tem aquela coisa de ser calmo... Eu acho assim, não é tanto a lei. Para fazer uma pesquisa com adolescente, a pessoa tem que estar bem instruída sabe, porque não é tão fácil, né?" (J.1.4).

A necessidade de um diálogo claro com o adolescente também foi ressaltada por uma pesquisadora, esse aspecto deve ser observado com qualquer voluntário de pesquisa, e não apenas com adolescentes: "é tentar explicar de uma forma que a pessoa consiga primeiro entender e consiga se sentir à vontade para querer saber mais, né. Para entender melhor o que está sendo explicado e até decidir para não participar (...) Eu acho que o consentimento é isso, não é a assinatura, não é a gente ter a segurança legal que a gente cumpriu uma etapa da pesquisa, mas a pessoa saber do que ela está participando" (P.2).

\section{Consentimento informado}

Apesar de uma das pesquisadoras considerar a obtenção do consentimento informado como um processo, as outras consideraram que o mesmo era obtido com a simples assinatura do TCLE. Hardy et al. 21 concluíram, num estudo sobre o consentimento informado e a experiência de pesquisadores, que estes confundiram o TCLE assinado com o cumprimento do conceito de obtenção de consentimento esclarecido.

Outro autor 18 considerou que o consentimento informado se obtém através de um pro- cesso. Esse é composto de: precondições (capacidade para entender e decidir; voluntariedade no processo de tomada de decisão), elementos da informação (explicação sobre riscos e benefícios; recomendação de uma alternativa mais adequada; compreensão sobre riscos, benefícios e alternativas) e elementos do consentimento (decisão em favor de uma opção, dentre um mínimo de duas propostas; autorização para a realização dos procedimentos propostos).

A assinatura do termo é apenas uma etapa do processo de obtenção do consentimento informado. Todas as pesquisadoras citaram a necessidade da assinatura do termo por um responsável, caso o participante seja menor de idade. Uma delas acreditava que o responsável poderia ser um adulto que estivesse acompanhando o adolescente. Entretanto, segundo a Resolução (Capítulo III, item 3g), a assinatura deve ser do responsável legal pelo menor 4 : “...os menores [de idade] teriam que estar sendo acompanhados ou, talvez com um responsável, ou com um adulto (...) Precisa que um responsável também esteja assinando esse documento. Que esse responsável sendo maior de idade: sendo mãe, marido, um adulto né?" (P.1).

Somente uma pesquisadora assinalou que a Resolução 196/96 exige a assinatura dos responsáveis caso o sujeito não tenha capacidade civil (Capítulo II, item 16) e, portanto, à necessidade de se recorrer ao Código Civil para encontrar a definição de indivíduos incapazes legalmente. No entanto, não citou a falta de definição de quem é "relativamente incapaz" no mesmo Código 9, relevante para compreender a capacidade legal dos mesmos.

"A assinatura do consentimento livre e esclarecido e toda informação sobre a pesquisa deve ser feita para ele. Ele deve assinar, mas, também, deve ter a concordância dos pais, ou do responsável legal. E, de acordo com o Código Civil brasileiro, essa autonomia é adquirida depois dos 18 anos (...) A Resolução coloca o menor que não tem autonomia, não tem capacidade civil e aí a gente tem que ir até o Código Civil para saber quem é esse menor que não tem autonomia civil" (P.2).

\section{Opinião sobre a necessidade de assinatura do responsável legal no TCLE}

Uma pesquisadora considerou adequada a necessidade de autorização, através da assinatura, dos responsáveis para que o adolescente participe como voluntário de pesquisa: "então, eu acho que é necessário sim. (...) Se a gente for pensar no adolescente como cidadão, pensar no 
Estatuto da Criança e do Adolescente, não especificamente em pesquisa; é uma pessoa que está sob a guarda, a tutela e a responsabilidade de outra - de um adulto. Não que ele não tenha capacidade para decidir e de escolher, mas uma pesquisa é um experimento científico! (...) Eu concordo plenamente com esse artigo da Resolução. Sempre!" (P.2).

Semelhantemente, duas jovens afirmaram que, se o adolescente for dependente dos pais, ele deve pedir autorização: “depende, né? Se você estiver morando dentro da casa deles, sendo sustentado por eles, aí sim [os pais devem assinar o TCLE]" (J.2.3).

Uma das pesquisadoras ressaltou que, no processo de obtenção do consentimento, deve garantir-se que o indivíduo tenha compreendido as informações fornecidas e que o adolescente tem capacidade para decidir. Porém, ela concordou com a exigência da assinatura do responsável pelo fato de o menor estar sob a guarda de um responsável. As outras consideraram a exigência de assinatura do responsável legal inadequada em alguns casos: "mas eu acho que para participar de uma pesquisa, eu acho um pouquinho exagerado você ter que pedir para o responsável que assine (...) Mas em uma pesquisa em que a participação é a resposta de um questionário, isso eu acho que não teria assim uma diferença" (P.1).

As jovens foram questionadas sobre sua opinião a respeito da exigência da assinatura do termo pelo responsável legal autorizando sua participação. Elas consideraram necessário que seus pais soubessem da participação, mas que seu papel não era de proibir nem autorizar. "Eu acho que deveria ser decisão do adolescente próprio, porque é uma pesquisa não é nada mais, o nome não vai ser revelado nem nada, eu acho que não tem problema. [Os pais têm que] estar consciente que é uma pesquisa sobre adolescentes, né? Mas não ficar sabendo tudo o que ocorre na pesquisa, qual o tipo de pergunta que é feita, o que respondeu" (J.2.2).

Em um estudo que avaliou a opinião dos pais e dos filhos (menores de idade), inscritos em pesquisas de suscetibilidade genética, sobre consentimento informado, a visão geral dos adolescentes foi a de que eles deveriam ter o controle sobre qualquer decisão que os envolva. No entanto, eles acreditavam que crianças mais novas que eles têm menos capacidade de tomar decisões 22 .

Apesar de as pesquisadoras terem mencionado que cabe aos adolescentes decidirem a respeito de sua participação na pesquisa, consideraram complexo simplesmente suspender a necessidade da assinatura do representante legal, quando se tratasse de pesquisas que não fossem de opinião: "é aí é que tá, né? A partir do momento que a gente autoriza, que você libera para que esse adolescente possa estar respondendo, você também vai estar expondo ele a qualquer tipo de pesquisa. Entretanto, o que eu penso é que se alguém tiver interesse de estar fazendo alguma coisa não adequada, algum tipo de pesquisa não adequada com esse adolescente, ele nem vai pedir autorização para mãe e para o pai (...) então, assim, eu não sei, como é que a gente vai limitar: essa pesquisa pode, aquela não pode (...) Eu só acho que do jeito que está, está muito complicado" (P.3).

No estudo de Geller 22, pais e filhos concordaram que a autonomia dos filhos para tomar a decisão de participar de uma pesquisa depende do risco associado a ela. Segundo os participantes, há a necessidade do consentimento dos pais para o adolescente participar de pesquisas cujos procedimentos são invasivos. Um resultado semelhante foi obtido pelas entrevistas, algumas jovens - apesar de não terem conhecimento sobre os diferentes tipos de pesquisa - afirmaram que, se for uma pesquisa semelhante a que tinham participado, não haveria problema dela decidir sozinha. Ou seja, em pesquisas de opinião, elas poderiam decidir sozinhas - mesmo sem o consentimento dos pais: "é, desde que seja sobre essas coisas e não seja nada de errado, eu acho que a gente pode dar autorização sozinha" (J.1.3).

Tanto as opiniões das pesquisadoras quanto as das jovens (sobre a necessidade da assinatura dos pais, ou responsáveis legais, para a participação de adolescentes em pesquisa) podem estar associadas a alguns fatores. Um deles pode ser o tipo de pesquisa pela qual estavam envolvidas, todas eram pesquisas de opinião e não acarretavam nenhum risco vultoso. Há também a questão de as pesquisadoras terem em mente (quando responderam as perguntas) as voluntárias de suas pesquisas (mães adolescentes, muitas delas já casadas), o que pode ter proporcionado às pesquisadoras observarem essas adolescentes sob uma ótica diferenciada de outros adolescentes. Além desses fatos, quando as jovens foram entrevistadas para o estudo, elas já não eram mais adolescentes (com exceção de duas).

\section{Dificuldades}

Apesar da particularidade do grupo estudado, algumas dificuldades para se cumprir as exigências foram mencionadas. Na pesquisa de Hardy et al. 23, mais da metade dos pesquisadores entrevistados considerou a Resolução 196/96 
difícil de ser cumprida integralmente. No atual estudo, uma pesquisadora citou o problema de manter a confidencialidade e a privacidade (Resolução 196/96 4, capítulo III, item 3h) da fonte das informações (o adolescente) ao ter que pedir que o responsável legal assine o termo: "se você tem uma pesquisa que você vai falar sobre aborto, sobre uso de drogas, sobre, enfim, sexualidade em geral, como é que você vai chegar para uma mãe e dar um termo de consentimento desses? Sendo que você tem que colocar o título na carta de consentimento, de tudo da pesquisa, e aí? Ele [adolescente] vai ficar à vontade?" (P.3).

De fato, uma das jovens informou que seus pais ficaram sabendo de sua participação na pesquisa alguns meses depois, porque não tinham conhecimento sobre sua gravidez. Isso ocorreu, pois as voluntárias da pesquisa que ela participou eram adolescentes grávidas (ela participou da Pesquisa 1): “[e seus pais ficaram sabendo da sua participação na pesquisa?] Não. Quando ela [mãe] ficou sabendo que eu já estava grávida, eu já tava de uns quatro meses para lá!" (J.1.2).

Com relação à confidencialidade e privacidade, as Guidelines for Research on Reproductive Health Involving Adolescents [Diretrizes para Investigação em Saúde Reprodutiva em que Participam Adolescentes] 24 orientam que o adolescente pode dar seu consentimento sozinho, sem pedir autorização dos pais. Se houver necessidade da assinatura dos pais no termo de consentimento em uma pesquisa de saúde reprodutiva, eles podem ficar sabendo que seus filhos são sexualmente ativos.

As pesquisadoras também mencionaram que o fato de o responsável ter que assinar o termo pode ser uma barreira à participação do adolescente, pois, muitas vezes, o adolescente não está acompanhado do responsável. Isso gera maior demanda de tempo no período da coleta de dados na pesquisa, seja porque esse adolescente é excluído da pesquisa, seja porque se aguarda o adolescente trazer o termo assinado pelos responsáveis. Outra dificuldade citada, tendo-se em vista pesquisas realizadas com mães adolescentes, é o fato de muitas delas, ao terem filhos, estabelecerem uma união estável com seus companheiros 25.

“Em muitos casos, essas adolescentes já estavam morando sozinhas com o bebê e o pai da criança, que também era outro adolescente, $e$ nesse caso, você vai pedir autorização para quem?" (P.3).

Essa opinião mostra um desconhecimento por parte das pesquisadoras, pois, segundo o Código Civil 9, a incapacidade legal do menor cessa em alguns casos, como com o casamento. Isso é válido não apenas para o casamento civil, mas também para as uniões estáveis.

\section{Conhecimento e opinião a respeito}

da faixa etária da adolescência

Todas as pesquisadoras citaram a definição de adolescência da OMS 1 quando perguntadas se conheciam algum documento como fonte de definição. Também citaram o Código Civil 9 e o Estatuto da Criança e do Adolescente 20. Ao ser solicitada sua opinião a respeito das definições citadas por elas, pareceu não se sentirem à vontade para falar a esse respeito. Para as pesquisadoras, a faixa etária para adolescência da OMS 1 é muito ampla, e a idade não é suficiente para se definir alguém como adolescente, apesar de atentarem para a necessidade de se adotar um padrão para se fazer pesquisas: " $a h$, a gente acha 10 anos criança ainda (...) Assim, na prática, ninguém se sente adolescente com 19 anos. (...) Eu deixava entre 12 e 18 anos [risos]. A problemática está nessa faixa etária, não é? É o que eu te dizia, é muito ampla. Então, de repente, você tem quase crianças" (P.1). "Não, a faixa etária é um critério até cômodo, né? Porque você se ampara, né? Você determina qualquer norma, qualquer procedimento nessa faixa etária. Agora, se a gente for pensar no conceito de adolescência, o significado que tem de mudanças, né? (...) Se isso traria alguma implicação em pesquisa, não sei" (P.2).

Para uma pesquisadora, o problema de o pesquisador definir se o adolescente tem ou não capacidade de decidir autonomamente participar da pesquisa poderia ser resolvido com a diminuição da amplitude da faixa etária da adolescência: "se não fosse tão ampla, então eu acho que poderia ser mais fácil [definir a capacidade de autonomia]" (P.1).

\section{Autonomia}

As pesquisadoras, ao serem questionadas sobre sua opinião a respeito da autonomia dos adolescentes para aceitarem participar como sujeitos de pesquisa, afirmaram não poder generalizar: "eu acho que não se pode dizer, de forma geral, se eles todos têm autonomia (...) isso, de autonomia, é muito particular, individual, né? Obviamente que a maturidade vai levando a uma autonomia, mas, não quer dizer que sendo menor [com pouca idade] não vai ter autonomia" (P.1).

Ao mesmo tempo consideraram que os adolescentes já poderiam tomar decisões para participar como voluntários de pesquisa, e ela ci- 
tou o exemplo daquelas que foram voluntárias de sua pesquisa: "por que a gente vai considerar que ela [a adolescente] não tem autonomia se ela resolve iniciar sua atividade sexual? Muitas vezes, a menina chega com 17, 16 anos é casada, e nós não temos mais a obrigação de pedir acompanhante para ela, quando está casa$d a "$ (P.1).

Esse mesmo argumento pode se encontrado nas diretrizes para se fazer pesquisa em saúde reprodutiva com adolescentes como voluntários 24 . Segundo essas diretrizes, os pesquisadores, ao suprimir a autorização dos responsáveis, não cometem nenhuma transgressão jurídica, caso os adolescentes sejam sexualmente ativos (ou estão a ponto de sê-lo). Além de a pesquisa oferecer uma relação risco-benefício favorável. Uma pesquisadora afirmou que os adolescentes têm essa capacidade de decisão, apesar de concordar com a exigência da assinatura dos responsáveis legais: "eu acho que sim, muita gente diz que não, mas eu acho que os adolescentes têm sim [capacidade de decisão]. Mas, eu acho que, volto a insistir nisso, desde que a gente saiba como facilitar esse processo de pensar e tomar a decisão. Acho que nós devemos ser facilitadores (...) Eles decidem sobre muitas coisas na vida deles, né? E eu acho que eles têm que ter essa autonomia para decidir! (...) Agora, não é fácil construir essa autonomia. É muito fácil obter o consentimento [assinatura do TCLE], né? Mas é muito difícil você ter certeza que a pessoa entendeu e que ficou claro para ela" (P.2).

A maioria das jovens afirmou que se considerava capaz de decidir sozinha se aceitava ou não participar de uma pesquisa. Apesar de elas se considerarem capazes, acreditavam que nem todos os adolescentes o são, pois afirmaram que não são todos que têm maturidade para isso. "Não, nem todos. Têm alguns [adolescentes] que têm responsabilidade. Hoje em dia, bastante não tem... é imaturo" (J.2.1).

De acordo com a literatura, autonomia está relacionada com a capacidade de autodeterminação e essa capacidade se amadurece durante a vida da pessoa 10 , assim pode-se inferir que a autonomia é adquirida de acordo com as vi- vências de cada indivíduo. Portanto, não cabe a outros determinar a autonomia de alguém. Segue-se, então, que todo ser humano tem direito de tomar as decisões relativas a si mesmo, a menos quando traga prejuízo para outros indivíduos 11 .

Enquanto os pesquisadores observarem a bioética sob uma ótica deontológica, ou seja, apenas como regras a serem seguidas, respeitar a autonomia dos adolescentes torna-se impossível praticamente. Ter informações sobre as regras e normas para participação de adolescentes em pesquisa, sem conhecê-las em profundidade, sem apreender o conceito de consentimento livre e esclarecido, sem refletir sobre qual concepção de adolescente está presente, não é suficiente para garantir a participação autônoma como voluntário de pesquisa.

O conhecimento das pesquisadoras sobre as normas para realização de pesquisas com adolescentes mostrou-se limitado, apesar de estarem vinculadas a instituições universitárias ou centros de pesquisa. Entretanto, as opiniões das participantes desse estudo não representam o universo dos pesquisadores brasileiros. Este estudo mostrou, também, algumas dificuldades enfrentadas pelas pesquisadoras que trabalham com voluntários de pesquisa adolescentes.

Portanto, aponta para a necessidade de uma discussão ampla sobre a Resolução 196/96 e sua aplicabilidade, especialmente a respeito da participação de adolescentes em pesquisas. Logo, uma possível sugestão é que fosse elaborada uma emenda à Resolução 196/96 específica para pesquisas em que os voluntários são adolescentes. Também poderiam existir algumas formas de informar os adolescentes sobre sua participação em pesquisas, através de folhetos explicativos numa linguagem acessível a esse grupo. É necessário que os adolescentes estejam informados sobre as normas para que, quando convidados a participar de uma pesquisa, possam avaliar a qualidade das informações recebidas e assim decidir de forma realmente informada. 


\section{Resumo}

Apresentam-se resultados de um estudo que avaliou o conhecimento e a opinião de pesquisadoras e jovens, que haviam sido sujeitos de suas pesquisas sobre as normas legais referentes à participação de adolescentes como sujeitos de pesquisa; a capacidade dos adolescentes decidirem de forma autônoma; e o processo vivenciado pelos adolescentes quando aceitaram serem sujeitos. O estudo foi qualitativo, com amostra intencional, definida pelo critério de saturação das informações. Entrevistaram-se três pesquisadores que tinham adolescentes como sujeitos de uma de suas pesquisas e nove destes jovens. Os dados foram coletados através de entrevista semidirigida, gravada. Todas as pesquisadoras conheciam algum documento legal relativo à participação de adolescentes como voluntários de pesquisa. As jovens surpreenderam-se, pois não sabiam da existência das mesmas, entretanto, as consideraram necessárias para proteger os adolescentes. Em geral, as pesquisadoras e as jovens consideraram que os adolescentes têm capacidade para decidir de forma autônoma participar como voluntários de pesquisa. As jovens afirmaram ter decidido sua participação conscientemente.

Adolescente; Ética em Pesquisa; Consentimento Informado

\section{Colaboradores}

F. Guariglia participou da revisão de literatura, elaboração do projeto, coleta de dados, análise dos resultados e redação do artigo final. S. F. Bento colaborou na revisão do artigo final. E. Hardy contribuiu na orientação do projeto, análise dos resultados e revisão do artigo final.

\section{Agradecimentos}

As autoras agradecem à contribuição financeira da CAPES (Coordenação de Aperfeiçoamento de Pessoal de Nível Superior) e do FAEP/UNICAMP (Fundo de Apoio ao Ensino e à Pesquisa/Universidade Estadual de Campinas), ao apoio logístico do CEMICAMP (Centro de Pesquisas Materno-infantis de Campinas) e às pessoas que contribuíram para que este estudo fosse realizado.

\section{Referências}

1. Organização Mundial da Saúde. Child and adolescent health and development. http://www. who.int/child-adolescent-health (acessado em 08/Set/2004).

2. Instituto Brasileiro de Geografia e Estatística. População residente total, por sexo e grupos de idade. Censo demográfico 2000. http:/ / www.ibge. gov.br (acessado em 08/Set/2004).

3. Associação Médica Mundial. Declaração de Helsinki VI. http://www.bioetica.ufrgs.br/helsin6. htm (acessado em 22/Set/2004).

4. Conselho Nacional de Saúde. Ministério da Saúde. Resolução no 196/96 sobre pesquisa envolvendo seres humanos. Bioética 1996; 4 (2 Suppl):1525.

5. The National Commission for the Protection of Human Subjects of Biomedical and Behavioral Research. The Belmont Report: ethical principles and guidelines for the protection of human subjects of research. http://ohsr.od.nih.gov/guidelines/belmont.html (acessado em 22/Set/2004).

6. Pessini L, Barchifontaine CP. Problemas atuais de bioética. 6ạ Ed. São Paulo: Edições Loyola; 2002.

7. Council for International Organizations of Medical Sciences/World Health Organization. International ethical guidelines for biomedical research involving human subjects. http://www. cioms.ch/frame_guidelines_nov_2002.htm (acessado em 22/Set/2004).

8. Santelli JS, Smith-Rogers A, Rosenfeld WD, DuRant RH, Dubler N, Morreale M, et al. Guidelines for adolescent health research. A position paper of the Society for Adolescent Medicine. J Adolesc Health 2003; 33:396-409.

9. Brasil. Código civil: lei n. 10.406 de 10/01/2002. 1a Edição. São Paulo: Saraiva; 2003.

10. Goldim JR. Princípio do respeito à pessoa ou da autonomia. http://www.bioetica.ufrgs.br/autonomi.htm (acessado em 04/Out/2004).

11. Segre M, Silva FL, Schramm FR. O contexto histórico, semântico e filosófico do princípio de autonomia. http://www.portaldomedico.org.br/ revista/biolv6/conthistorico.htm (acessado em 04/Out/2004).

12. Fortes PAC, Sacardo DP. Ética na assistência à saúde do adolescente e do jovem. In: Área de Saúde do Adolescente e do Jovem, Secretaria de Políticas de Saúde, Ministério da Saúde, organizador. Cadernos, juventude saúde e desenvolvimento. v. 1. http://www.adolec.br/bvs/adolec/P/cadernos/ capitulo/cap15/cap15.htm (acessado em 04/Out/ 2004).

13. Denzin NK, Lincoln YS, editors. Handbook of qualitative research. Thousand Oaks: Sage Publications; 1994.

14. Patton MQ. Qualitative evaluation and research methods. London: Sage Publications; 1990.

15. Fonseca JS, Martins GA. Curso de estatística. 5a Ed. São Paulo: Editora Atlas; 1994.

16. Turato ER. Tratado da metodologia da pesquisa clínico-qualitativa. Petrópolis: Editora Vozes; 2003.

17. Minayo MS. O desafio do conhecimento: pesquisa qualitativa em saúde. São Paulo: Editora Hucitec/Rio de Janeiro: ABRASCO; 2000. 
18. Clotet J, Goldim JR, Francisconi CF. Consentimento informado e a sua prática na assistência e pesquisa no Brasil. Porto Alegre: EDIPUCRS; 2000.

19. Hardy E, Bento SF, Osis MJD, Hebling EM. Consentimento informado na pesquisa clínica: teoria e prática. Rev Bras Ginecol Obstet 2002; 24:407-12.

20. Brasil. Estatuto da criança e do adolescente: lei n 8.069 de 13/07/1990. 2a Ed. Brasília: Imprensa Nacional; 1997.

21. Hardy E, Bento SF, Osis MJD. Consentimento livre e esclarecido: experiência de pesquisadores brasileiros na área da regulação da fecundidade. Cad Saúde Pública 2004; 20:216-23.

22. Geller G, Tambor ES, Bernhardt BA, Fraser G, Wissow LS. Informed consent for enrolling minors in genetic susceptibility research: a qualitative study of at-risk children's and parents' views about children's role in decision-making. J Adolesc Health 2003; 32:260-71.
23. Hardy E, Bento SF, Osis MJD. Consentimento informado normatizado pela Resolução 196/96: conhecimento e opinião de pesquisadores brasileiros. Rev Bras Ginecol Obstet 2002; 24:59-65.

24. United Nations Development Programme/United Nations Population Fund/World Health Organization/Special Programme on Research, Development and Research Training in Human Reproduction. Guidelines for research on reproductive health involving adolescents. http://www.who. int/reproductive-health/hrp/guidelines_adolescent.en.html. (acessado em 04/Out/2004).

25. Instituto Brasileiro de Geografia e Estatística. Nupcialidade e fecundidade. Censo demográfico 2000. http://www.ibge.gov/home/estatitica/populacao/censo2000/nupicialidade_fecundidade/t abnupbr113.pdf (acessado em 04/Out/2004).

Recebido em 28/Out/2004

Versão final reapresentada em 17/Mai/2005

Aprovado em 13/Jun/2005 